\title{
A Brief Analysis of Health Care Reform Modes
}

\author{
Xuexia Wei, Shiqiang Zhang* \\ Medical Information College, Chongqing Medical University, Chongqing, China \\ Email: ${ }^{*}$ math808@sohu.com \\ Received December 2014
}

\begin{abstract}
By introducing the cases of health care reforms in Peoples' Hospital of Gaozhou City in Guangdong province and Shenmu county in Shaanxi province, namely, "Gaozhou mode" and "Shenmu mode", we investigate the different policies and effectiveness of the two modes and discuss the influences of government subsidies and market factors to health care reform in order to gain experience and inspiration of health system reform.
\end{abstract}

\section{Keywords}

Gaozhou Mode, Shenmu Mode, Public Hospital Reform, Health Care Reform

\section{Introduction}

As a worldwide difficult problem that is related to the livelihood of people, health care reform has always been an important content of study in many countries. On April 6, 2009, "The CPC Central Committee and State Council's opinions on deepening medical and health system reform” (hereinafter referred to as the new medical reform program) was announced, officially opening the prologue of a new round of China's medical and health system reform (referred to as the new health care reform). As typical experiments of new health care reform, "Gaozhou mode" and "Shenmu mode" have an important reference to carry on deeper and wider range of health care reform. This article compares and contracts the concrete policies and effects of the two modes, summarizes the experiences and existing problems, and provides new ideas for the health care reform in our country.

\section{The General Situations of the Two Medical Reform Modes}

\subsection{The General Situation of "Gaozhou Mode"}

"Gaozhou mode” is a brief name of "the operating mode of People’s Hospital of Gaozhou City”. As a countylevel public hospital, with almost no government compensation, Gaozhou Hospital adopted a series of measures creating a medical platform where patients could receive cheap and high quality health care services and realized the hospital, patients, government win-win situation, and thus being named "Gaozhou mode".

${ }^{*}$ Corresponding author. 
The concrete practice of "Gaozhou mode" mainly has the following several aspects: First, seriously dealing with the "three excesses" [1]: that is seriously dealing with drug abuse, excessive examination and excessive fees. Second, the "three high-voltage lines" [1] (also known as "three noes"): that is no receiving money and gifts from patients, no dinner appointment from patients and no patients rank classification. Third, "sunshine purchasing” [1]: that is to establish a temporary purchasing group, procurement personnel are temporarily transferred, and will be dissolved immediately after procurement. Fourth, "five black spots" management [2]: every mistake medical staffs make will be recorded as a black spot. When the black spots are up to five, the medical staff will be out. Fifth, second bargaining [3]: Gaozhou Hospital implements the "go with the bid not with the price" measure to determine the best purchasing object.

\subsection{The General Situation of "Shenmu Mode"}

Shenmu mode is a brief name of "Measures for the Implementation of Universal Free Medical Care in Shenmu County". Shenmu county ranks 92 in the top 100 counties in China, in the circumstance of the other top 91 counties having no try, Shenmu county is the first one to implement "universal free health care". Comprehensive free medical objects are those cadres, workers, urban and rural residents who have Shenmu membership accounts (except for residents who do not participate in cooperative medical system and basic medical insurance system for staff). Sections for outpatients carry out medical card system, each person can enjoy 100 yuan for outpatient subsidies, and the surplus funds in outpatient medical card can be carried over for use and inheritance. Inpatient reimbursements have the pay lines. Patients will pay if medical expense is less than the deductible, and the local government will pay for the money above the pay line if medical expense is more than the deductible. Another highlight in Shenmu health reform is to include the special examination and treatment such as organ transplantation as reimbursement contents, and the reimbursement limit is 300000 yuan per person per year.

In fact, Shenmu mode is not a true "universal free medical care", because the "people" here do not include everyone, but only include those who participate in the basic medical insurance. It is a kind of high level of "universal health care insurance". And the "free" is not generally understood. Bai Zhitang, the director of Health Bureau in Shenmu explains, universal free medical care system in Shenmu county is a new cooperative medical system, why it is called "universal free health care" is a political consideration of politicians. They strive to bring the maximum benefits to the people, without causing waste of medical funds and medical resources [4].

\section{The Progresses of the Two Medical Reform Modes}

\subsection{The Progress of "Gaozhou Mode"}

As a hospital in remote mountainous areas, Gaozhou Hospital's medical level is equivalent to that in the top three hospitals, but its medical expenses are almost half of them. So it once attracted patients from 23 provinces and 38 counties inland, and the patients from United States, Indonesia, Tanzania and other different countries and regions [5]. In 2006 and in 2010 Guangdong Provincial Health Office and the government were jointly issued "Decision on Learning from People's Hospital of Gaozhou City". They gave a high evaluation of Gaozhou mode, and hoped it could have a provincial and even a national promotion.

In January of 2013, Gaozhou Hospital was reported by CCTV that doctors there received kickbacks, some experts said this event marked the failure of "Gaozhou mode" [3]. As a healthcare reform star, it not only had no promotion, but did not maintain itself and finally failed itself.

\subsection{The Progress of "Shenmu Mode"}

In the first two months of the implementation of "free medical care", the need for hospitalization in Shenmu had a spurt growth. People who needed to be hospitalized had to make advance reservations, and all designated hospital beds were all put into use [6]. Many people worried whether "free health care" would not be sustainable because of overcrowding? Whether finance could afford? According to the public information in Shenmu, the amount of hospitalized patients reached a peak in the second month (April) and began to fall back from May in 2009.

In 2012, coal prices fell, Shenmu county, being rich because of coal, gradually was into crisis of coal market changes, lending collapse and rumors flying. Many people feared free medical care would be terminated due to 
government deficit, thus triggering the "7.15” thousands of people besieging the county’s government storm [7].

\section{The Problems of the Two Medical Reform Modes}

Gaozhou mode has problems as follows: first, it lacks of board governance system [8]. The Council shall be composed of the interests of the neutral, in order to ensure the public welfare of measures. Second, it lacks of a relatively complete system, and relies on the efforts of previous president Zhong Huanqing, once changing a leader, it is difficult to maintain the essence of Gaozhou mode. Third, it lacks of timely and appropriate government compensation mechanisms. The hospital takes small profits but quick turnover profit model, when the number of patients does not reach a certain number, if without timely corresponding compensation mechanism, the hospital will try to take money from the hands of patients, to support the development of the hospital, and this will produce the induced consumption behavior.

Shenmu mode has problems as follows: first, the industrial structure of a heavy reliance on coal exists a government revenue crisis. Once the coal industry is hit, the mainstay of the economy will collapse [7]. Second, moral risk and low efficiency risk exist. Once patients with ailments are over hospitalized, patients need to be hospitalized critically will have no chance to obtain medical services, thus resulting in inefficient health care. Third, cost control and supervision is difficult.

\section{The Experiences and Inspirations of the Two Modes}

\subsection{Pay Attention to People's Livelihood, Adhere to Public Welfare}

Throughout the two health care reform modes, whether "Gaozhou mode", or "Shenmu mode", they both paid attention to the most strongly reflected problems from the masses like "seeing a doctor too difficult and expensive" and strove to alleviate the difficulties and the burden of people seeing a doctor. The two modes made different attempts to improve the problem of seeing a doctor difficult and expensive with different methods. They both made important contributions to achieve universal access to basic health services. The direction and the concept of "Think what the masses would like to think, worry what people are worrying, solve what are problems to the masses" are worth learning to all hospitals.

\subsection{Perfect the Quantity and Quality of Government's Investments}

Although "Gaozhou mode" achieved a successful development with almost no government investments, it can not therefore think that the developments of public hospitals need no government investments. And we argue that lacking of appropriate and timely government compensations and investments is actually one important reason of the failure of Gaozhou mode. The universal free health care system that Shenmu implements are inseparable from the government investments.

The governments need to invest to health care, but how many the investments should be and how to input indeed need careful argumentation. For example, how many governments should invest to make people have access to basic medical services? How many to obtain the largest input-output? Should invest more on the supply-side or the demand-side? Should invest more to promote the development of top three hospitals or basiclevel hospitals? Should focus on treating or prevention? These all need careful argumentation.

\subsection{Draw Support from Market Forces Appropriately to Develop}

The main part of optimizing the allocation of healthcare resources should be the government, but when government investment is insufficient or missing, waiting and relying on government much is not the way. As long as the conditions are met, finding a way from the market and drawing support from market forces to optimize the allocation of resources is also a viable select [9]. The experience of "Gaozhou mode" tells us that, we can use price mechanism and market competition mechanism to allocate resources, coordinate the different roles of government and the market and thus walk out a road with economic and social benefit.

There are 14 hospitals in Shenmu county, one public hospital; the remaining 13 are all private hospitals [10]. Through the principle of "select the superior and eliminate the inferior", the government decides the designated medical insurance hospitals directly. This can establish competition mechanism between private hospitals and public medical institutions, and improve the medical service level and reduce medical price. 


\subsection{Establish an Integrated Social Medical Insurance of Urban and Rural}

China's new medical reform program points out that the ultimate goal of health insurance system reform is universal coverage, that is to achieve the unification of urban workers health insurance, urban residents health insurance and the new rural cooperative medical insurance. Shenmu regulations provide that any urban and rural residents with Shenmu membership accounts have the same implementation of outpatient medical card system and hospital reimbursement. It broke the boundaries between urban and rural areas, and also broke the identity boundaries of workers and residents, having a very important social significance.

\subsection{Perfect and Coordinately Build the Four Systems}

Complete health reform system includes public health service system, basic health care system, basic medical insurance system and basic drug supply system. The coordination between the four systems is the basis for the long-term stability of reform. Gaozhou and Shenmu respectively made explorations in the aspects of basic health care system and basic medical insurance system. But in the future, the perfection and development of public health service system and the pharmaceutical supply system and the coordination between the four systems will be further problems of new medical reform that need to be solved.

\section{Acknowledgements}

We thank Shanfa Yang for his help in preparing this manuscript.

\section{References}

[1] (2010) "Gaozhou Mode” Survey. Communists, 16, 27.

[2] Zhang, T.Y. (2011) “Gaozhou Mode”: Cutting off the Chain of Gray Interests Is the Key. Chinese Community Doctors, 4, 24.

[3] Xue, B.N., Zhou, S.B. and Yang, G.X. (2013) Gaozhou Mode Reform Fail? http://ndnews.oeeee.com/html/201301/13/15823.html

[4] Livelihood Weekly (2012) Shenmu Health Care Reform: The Sample? Existing Copies? http://business.sohu.com/20121119/n367359243.shtml

[5] Gui, K.Q. (2010) Gaozhou Mode Wonderful in Puerile. China Health Industry, 4, 16.

[6] Heng, J. (2011) Shenmu Livelihood Experiment: Go Forward in Questions. Rule by Law and Society, 6, 47-49.

[7] Yin, Z.P. (2013) Analyze the Crisis of Shenmu Mode. Theoretical Observation, 10, 160-161.

[8] China Economic System Reform Research Center for Public Policy Research (2010) The Advantages of Gaozhou Mode: Removing Administration and the Replicability of the Mode. Chinese Market, 50, 46-57.

[9] Gao, W.L. (2012) “Gaozhou Mode” and Public Hospital Reform. Modern Hospital, 5, 1-3.

[10] Niu, B. and Liu, Z.Y. (2013) A Brief Analysis of "Shenmu Healthcare Reform”. Chinese Health Service Management, 9, 646-647 + 679. 